\title{
The wonders of waste processing by termites
}

\author{
A. H. Hussein \\ Industrial Microbiology and Applied Chemistry program, \\ Alexandria University, Egypt
}

\begin{abstract}
The aim of this research is to demonstrate how to use the ecological niche of termite colonies for the benefit of humans. It is known that termites feed on papers wastes, particularly cardboard. In a trial experiment to demonstrate this capability it was found that termites produce hydrogen as a by-product and wastes of high potassium, phosphorous, and nitrogen content. It was then proposed to demonstrate the feasibility of using termites for getting rid of wastes, to increase the soil fertility and to produce hydrogen as a source for renewable energy. To prove the hypothesis, information about the ecology of termites and its favourable conditions in terms of temperature, moisture and preferable food sources was collected. Accordingly, several experiments were conducted using a designed Psammotermes hybostoma hydrogen bioreactor (P.H.H. bioreactor) that was constructed for growing a colony of termites on wastes of cardboard as a food source at different temperatures and constant moisture conditions. Results showed that if we use a medium sized colony (about 2 million termites) then it can produce about 660 litres of hydrogen every 24 hours. It is therefore concluded that many environmental problems can be solved using termite colonies. Solid wastes can be managed by the digestion of paper and cardboards in the termites' gut. Also, soil present in the P.H.H. bioreactor can be used as a valuable fertilizer and the hydrogen produced can be used as a renewable source of energy.
\end{abstract}

Keywords: termites, hydrogen production, soil fertility, Psammotermes hybostoma hydrogen bioreactor, renewable energy, environmental problems.

\section{Introduction}

A termite resembles an ant in appearance and partially in the way it lives. Termites have pale brown to white bodies with a darker head and have no waist between the thorax and the abdomen. But, even though they look like ants, 
termites have very different characteristics and abilities [1]. Termites live on almost every continent except in Polar Regions. Termite species live in a perfect social order and are classified into three groups according to where they live: underground termites, above ground termites and dry wood termites [2, 3]. A typical colony contains workers, soldiers, and reproductive individuals of both genders, sometimes containing several egg-laying queens [1, 3]. There are approximately 2,600 species of termites described with perhaps 500-1000 species still left to be described [4]. The most recent higher classification splits those species into nine extant families [4]. Hafez [5] stated that there are at least 11 species of termites in Egypt, among which, 8 species are ground-nesting or subterranean. The most abundant subterranean termite species in Egypt are the "harvester termite", Anacanthotermes ochraceus (Burmeister) (order: Isoptera, family: Hodotermitidae) and the "sand termite" Psammotermes hybostoma (Desn.) (order: Isoptera, family: Rhinotermitidae) [6, 7]. Termites feed on any cellulose containing material $[8,9]$. They produce hydrogen by breaking down the polymers into simple sugars, by fermenting bacteria in the termite's gut, using enzymes that produce hydrogen as a by-product [10].

This research discusses the possibility of using the termite's way of life as a means of creating hydrogen, as a clean and renewable source of energy and to increase the amount of nitrogen, phosphor and potassium, in addition to solving organic waste problems in order to save our environment.

\section{Materials and methods}

\subsection{Termite species}

The termite species that were used in this study were Psammotermes hybostoma (Isoptera: Rhinotermitidae) and they were obtained from natural colonies in Ismailia and Aswan in Egypt (Figure 1) [11]. In the laboratory, the termites were maintained on ribbed cardboard in a colonial section in the P.H.H. bioreactor. Worker termites were used for all the experiments.

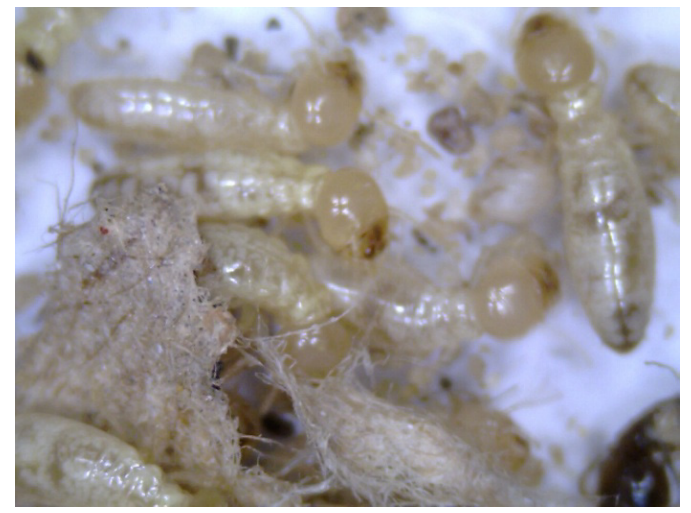

Figure 1: $\quad$ Psammotermes hybostoma worker sand termites. 


\subsection{P.H.H. bioreactor (Psammotermes hybostoma hydrogen bioreactor)}

The P.H.H. bioreactor (Figure 2) is designed to simulate a termite colony and to provide the termites with suitable conditions in which they are able to produce a high amount of hydrogen. The P.H.H bioreactor is divided into three parts; the colonial part, the acclimatization part and the hydrogen collection part.

\subsubsection{Colonial part}

The termites were maintained in a glass pool $(40 \mathrm{~cm}$ in height $\times 15 \mathrm{~cm}$ in width $\times 15 \mathrm{~cm}$ in length) filled up to its three quarter level with wet soil. Ribbed cardboard, which is a special cardboard (Figure 2), is provided for termites as a tunnel where they can live, as a source of food and has a provider of a high amount of cellulose and humidity. This part of the P.H.H. bioreactor must be tightly closed.

\subsubsection{Acclimatization part}

The glass pool $(50 \mathrm{~cm}$ in height $\times 25 \mathrm{~cm}$ in width $\times 25 \mathrm{~cm}$ in length) is filled with water. Two items were put inside of it; a heater responsible for raising the temperature of the bioreactor and maintaining the high humidity conditions needed by termites and a thermometer used to determine the temperature of the colony.

\subsubsection{Security and safety precautions in the bioreactor}

Beside the water in the outer glass pool, which prevents the termites from escaping, the P.H.H. bioreactor is made up of glass, which cannot be consumed by termites and cannot be easily climbed.

\subsubsection{Collection of gas over the water part}

The setup for the collection of gas over water involves a container (P.H.H bioreactor) in which the reaction takes place and a gas collection container filled with water and inverted into a reservoir of water. The gas that evolves from the reaction is collected by attaching one end of a hose to the reaction container and inserting the other end up into the inverted gas collection bottle. As the gas is created it will displace water from the bottle. The volume of gas can be determined by the amount of water that is displaced by the gas [12].

\subsubsection{Procedure of hydrogen production from Psammoterms hybostoma}

Hydrogen production experiments were conducted in the P.H.H. bioreactor. Before putting a known number of termites into the colonial part of the P.H.H. bioreactor, the colonial part was prepared by adding sterilized wet sand until it was three quarters full $(30 \mathrm{~cm}$ in height).

After each test, this part was cleaned and replaced by new wet sand before starting another test. The water is added to the acclimatization part and then the temperature is fixed. After that the P.H.H. bioreactor is tightly closed.

Because hydrogen has the lightest weight it was collected and detected by the collection of the gas-over-water method [12]. The experiments were performed at different time intervals, temperatures and numbers of termites to examine the 
amounts of hydrogen produced. To determine the suitable time required for the hydrogen production experiment, all other variables, numbers of termites, temperatures and types of food were fixed. To determine the suitable temperature for hydrogen production from Psammotermes hybostoma, the number of termites, number of hours and type of food were fixed. For examining the effect of the number of termites on the amount of hydrogen produced all other variables including temperature were fixed.
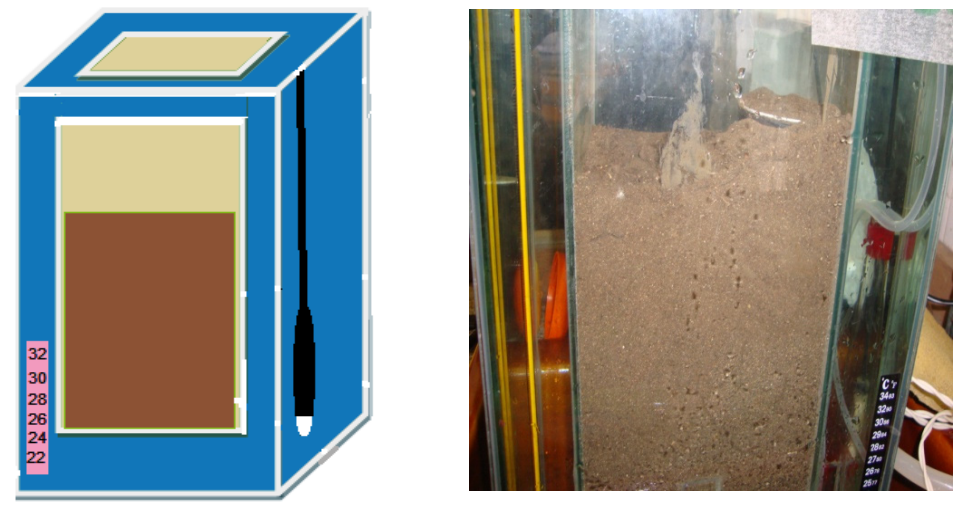

Figure 2: Design and photo of hydrogen Psammotermes hybostoma bioreactor.

\subsection{The effect of termites on the P.H.H. bioreactor soil fertility experiment}

After the effective amount of time, the number of termites and the temperature from the experiment on hydrogen production for Psammoterms hybostoma was determined and four samples of soil were collected from the P.H.H. bioreactor before and after 72 hours, which were analyzed at SWUIST (Soil and Water Activity of Information, Services and Training) [12] for phosphorous, potassium and nitrogen.

\section{Result and discussion}

\subsection{Hydrogen production}

Twelve experiments were carried out to determine the effect of time, numbers of termites and the temperature during hydrogen production from Psammoterms hybostoma (Table 1).

\subsubsection{Number of hours}

In the first three experiments 450 termites were used and cardboard was used as a source of food at $34^{\circ} \mathrm{C} \pm 2$. Hydrogen production was too small to be detected, so the number of hours was increased gradually from $12 \mathrm{~h}$ (experiment 1 ) to $24 \mathrm{~h}$ (experiment 2), to $48 \mathrm{~h}$ (experiment 3) and $72 \mathrm{~h}$ (experiment 5). During these 
experiments, it was noticed that termites built some tunnels in the soil, which is a remarkable sign of termite activity. The $4^{\text {th }}$ experiment was performed in a test tube with only 10 individuals. A small amount of hydrogen was detected $(2.5 \mathrm{ml})$ and there was a bad smell due to cardboard fermentation. Termites died because of the condensation of water on the inner surface of the tube.

For the next three experiments (5,6 and 7) 450 termites were used and cardboard was used as a source of food at different temperatures (the temperature was $34^{\circ} \mathrm{C}$ in experiment 5 , and $30^{\circ} \mathrm{C}$ in experiments 6 and 7), in order to examine the temperature effect on hydrogen production from termites as shown in Table 1.

\subsubsection{Number of termites}

\subsubsection{Improved P.H.H. bioreactor (I.P.H.H. bioreactor)}

After performing seven experiments using the P.H.H. bioreactor and the determination of the suitable temperature and number of hours for hydrogen production from $P$. hybostoma, it was necessary to improve the bioreactor by making it smaller and better sealed; hence the P.H.H. bioreactor was improved. The I.P.H.H. bioreactor (Figure 3) is a plastic jar $(5 \mathrm{~cm}$ radius, $15 \mathrm{~cm}$ height) with one outlet at the top of the container for hydrogen collection.

Experiments 8-12 were performed in the I.P.H.H. bioreactor and cardboard was used as a source of food at $30^{\circ} \mathrm{C} \pm 2$, while different numbers of termites were used: in the $8^{\text {th }}$ experiment 100 individuals, in the $9^{\text {th }}$ experiment 70 individuals and in the $10^{\text {th }}$ experiment 57 individuals. In experiments 11 and 12 , 350 individuals were used, and the number of hours was increased to 120 hours. In these two final experiments a high amount of hydrogen was produced and one could observe that tunnels were built by the termites. Drops of water on the inner surface of the bioreactor could also be observed.

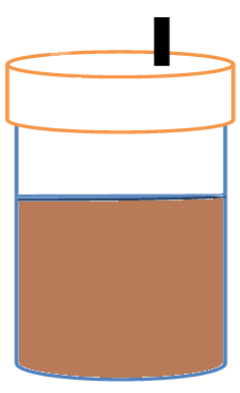

Figure 3: Improved P.H.H. bioreactor.

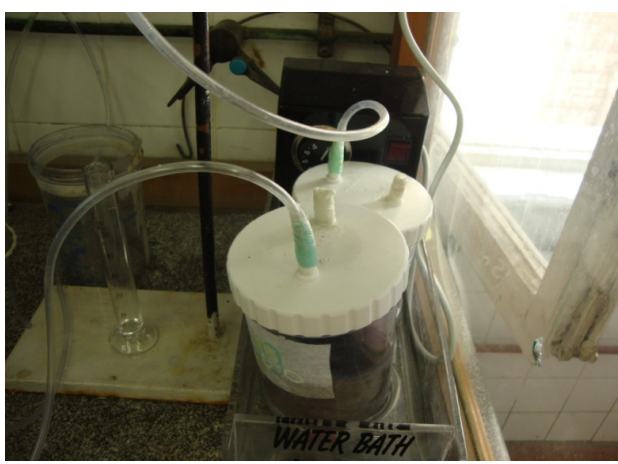




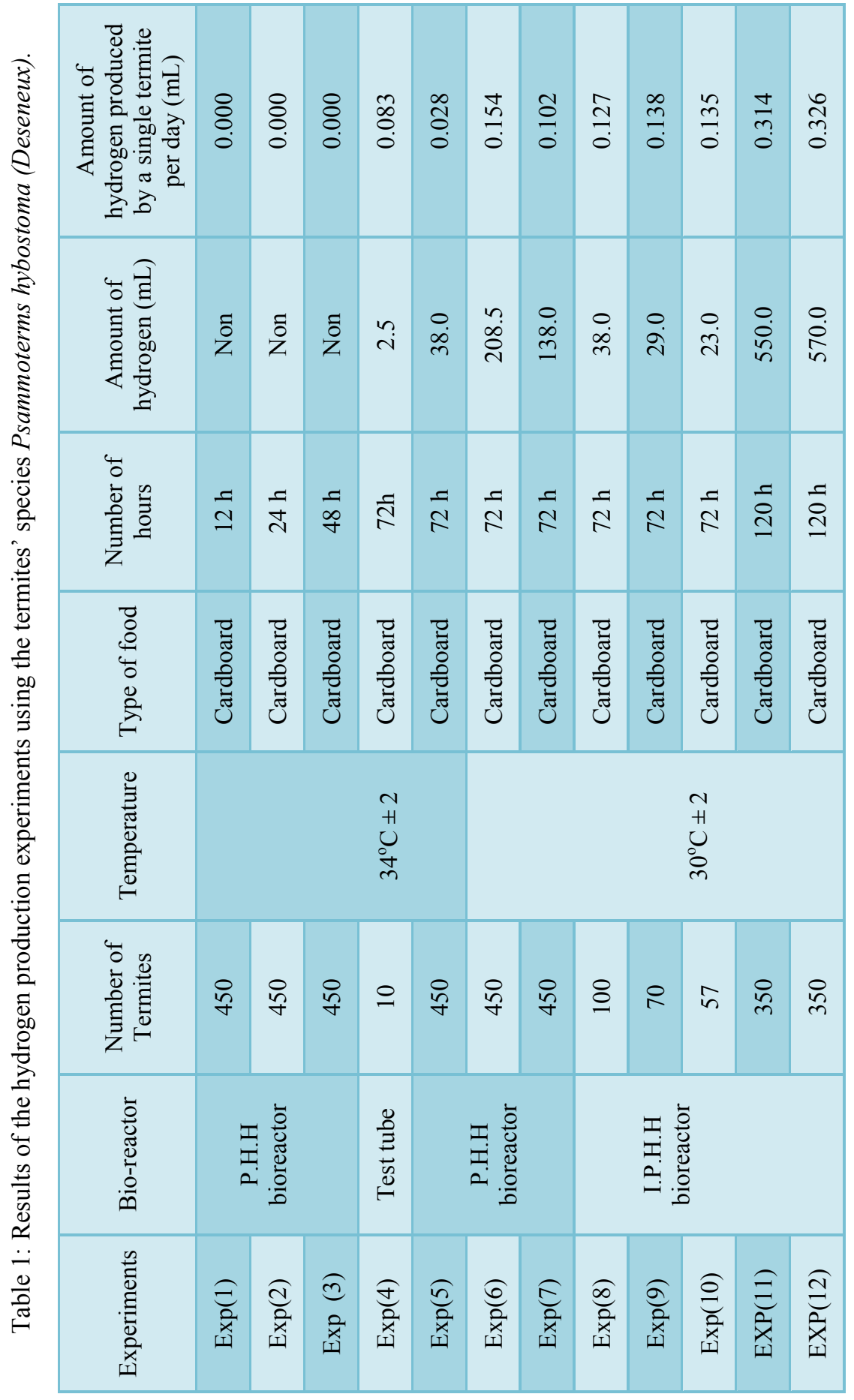


From these results, three relations can be estimated. The first demonstrates the relation between the amount of hydrogen produced and the number of hours (Figure 4), the second shows the relation between the temperature and the amount of hydrogen produced (Figure 5) and the third demonstrates the relation between the number of termites and the amount of hydrogen produced (Figure 6).

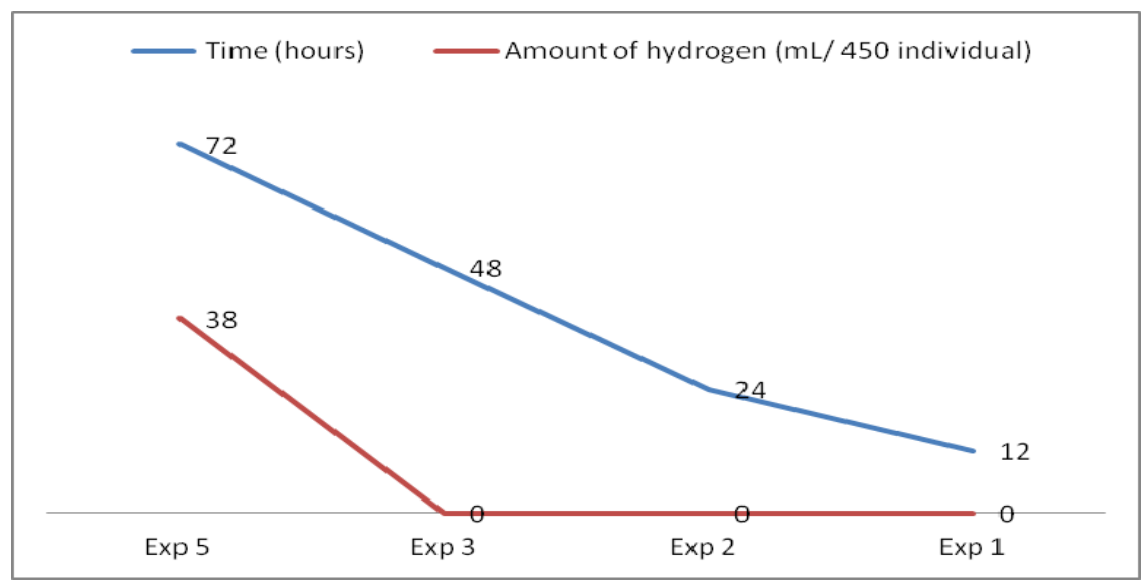

Figure 4: The relation between number of hours and the amount of hydrogen produced.

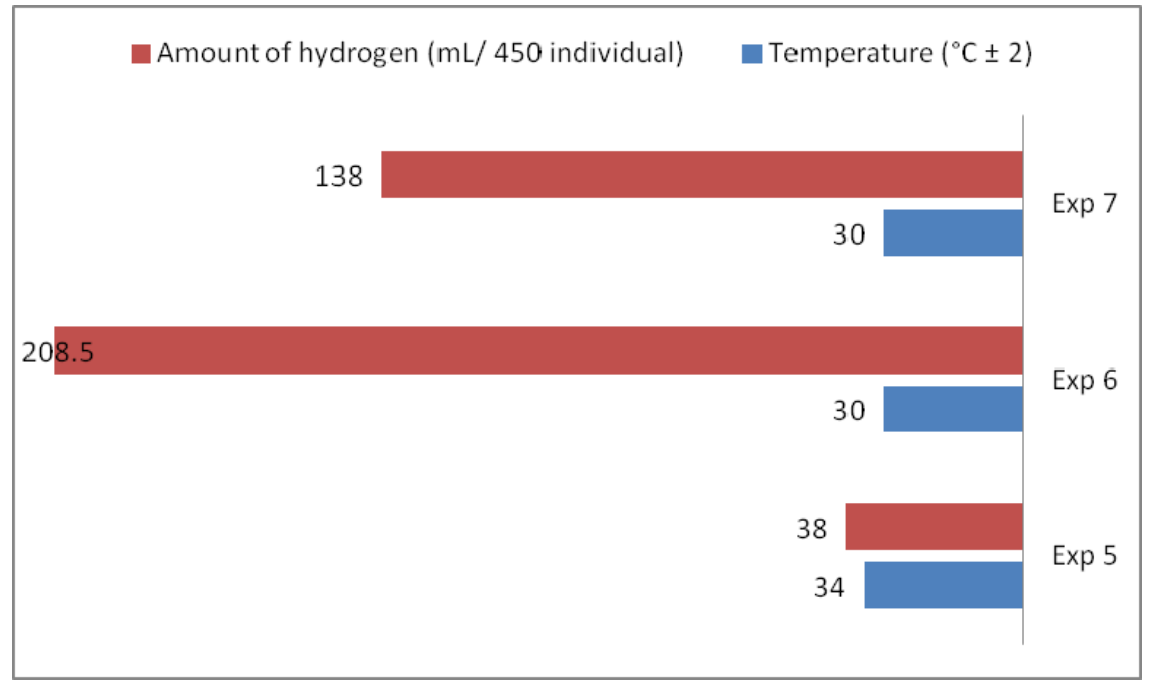

Figure 5: The relation between temperature and amount of hydrogen produced. 


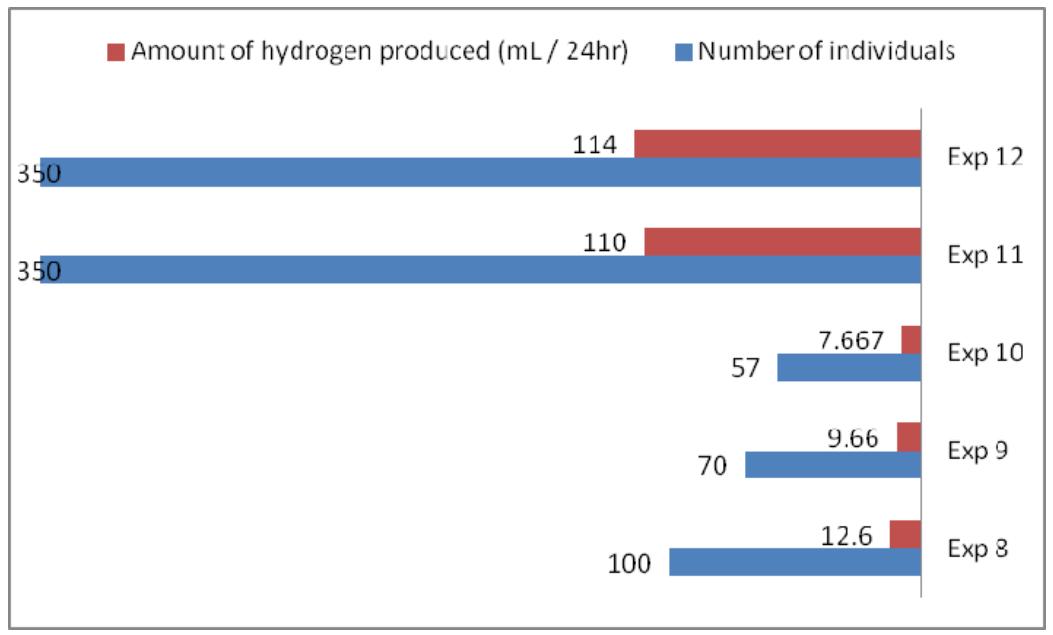

Figure 6: The relation between the number of individuals in the I.P.H.H. bioreactor and the hydrogen produced per 24 hours at $30^{\circ} \mathrm{C} \pm 2$ with cardboard as the source of food.

\subsection{Soil fertility}

Four samples of soil were collected. The first sample was taken before adding the soil into the colonial part of the improved P.H.H. bioreactor (I.P.H.H. bioreactor). The three remaining samples were taken from a different I.P.H.H. bioreactor after 120 hours (at $30^{\circ} \mathrm{C}$, with 350 individuals and using cardboard as a food source for the termites, experiment 11). The results show a variety of increases in the amounts of potassium, phosphorus and nitrogen in the soil of the I.P.H.H. bioreactor. (Table 2, Figure 7).

Table 2: The soil fertility analysis of four samples from I.P.H.H. bioreactor.

\begin{tabular}{|c|c|c|c|}
\hline Samples & Potassium & Phosphorous & Nitrogen \\
\hline $\begin{array}{c}|c| \\
\mathrm{MgKg}^{-1} \\
\text { Sontrol } \\
\text { sample }\end{array}$ & 810 & 79.2 & 77 \\
\hline $\begin{array}{c}\text { Second } \\
\text { Sample }\end{array}$ & 810 & 85 & 140 \\
\hline Third sample & 850 & 80.6 & 84 \\
\hline Fourth sample & 900 & 88 & 105 \\
\hline
\end{tabular}






Figure 7: $\quad$ Soil analysis of four samples.

\section{Conclusion}

This research demonstrates how to use the ecological niche of termite colonies for the benefit of humans. It demonstrates the possibility of using termites for eradicating wastes in order to produce hydrogen as a source for renewable energy and for increasing the soil fertility.

Seven experiments were carried out using a designed Psammoterms hybostoma P.H.H. bioreactor to determine the effect of time, the numbers of termites and the temperature of the hydrogen production using the termite species Psammoterms hybostoma. The bioreactor was improved to a smaller and more sealed bioreactor and was used in 5 more experiments.

The efficiency of the I.P.H.H. bioreactor was better than the first one for hydrogen production. Ribbed cardboard is considered the best food for termites because it provides them with tunnels, food and the moisture they need. The results show that one individual termite can produce about $0.33 \mathrm{~mL}$ hydrogen $/ 24 \mathrm{~h}$, which means that a medium sized colony (about 2 million individuals) can produce about 660 liters of hydrogen every 24 hours. The temperature affects the amount of hydrogen produced. The most effective degree of temperature was $30^{\circ} \mathrm{C} \pm 2$. The number of termites also affects the amount of hydrogen produced. As the number increases the hydrogen production rate also increases. Also, soil present in the P.H.H. bioreactor can be used as a valuable fertilizer. The results show an increase in the amount of both phosphorus and nitrogen in the soil of the bioreactors. 


\section{Acknowledgements}

I would like to thank my parents for their support. Sarah Alaa ElShater, Prof. Sherine Nabil Khattab, Prof. Doaa Ghareb, Prof. Mohammed Hassan Abo El Yousser, Prof. Boushra Salem, Prof. Aly Mourgan, Prof. Manal Fawzy and Prof. Ayman El-Faham at the Faculty of Science, Alexandria University are thanked for their scientific advice and support. The team of experts at the Bibliotheca Alexandrina is also thanked for their support.

\section{References}

[1] Mueller, U.G. \& Gerardo, N. Fungus-farming insects: Multiple origins and diverse evolutionary histories, proceeding of the national academy of sciences of United States of America, 99(24), pp. 15247-15249, 1999.

[2] Yahya, H. (Ed), the miracle of termites. Global publishing, Turkey, pp. 139, 2007.

[3] Hopkins, J.D., Subterranean Termite Identification and Biology, Agriculture and Natural Resources, University of Arkansas System, http://www.uaex.edu/Other_Areas/publications/pdf/FSA-7061.pdf.

[4] Eggleton, P., Biology of Termites: A Modern Synthesis, chapter 1. Springer-Dordrecht Heidelberg London New York. pp. 1-26, 2011.

[5] Hafez, M. Highlights of the termite problem in Egypt. Sociobiology, 5(2), pp. 147-154, 1980.

[6] Said, W. A., Ecological and toxicological studies on Family Hodotermitidae. M. Sc. Thesis, Faculty of Agriculture, Ain Shams University, pp. 128, 1979. 2003.

[7] Ali, A.M., Control of termites in Egypt-present and future. Sociobiology, 5(2), pp. 211-212, 1980.

[8] Harris, W.V., Termites their recognition and control. Longmans, London, pp. 187, 1961.

[9] El-Sherif, S.I., Rashad, H.M., Belal, M.H., El-Sebay, Y.M. \& Abd El-Latif N.A., Horizontal and Vertical Movement of Chloropyrifos (Dursban 48\%) in Soil and its Biological Activity on the Workers of two Subterranean Termite Species, Research Journal of Agricultural Sciences, 2(1), pp. 01-07, 2011.

[10] Termite Power; the U.S. Department of Energy Joint Genome Institute, United States of America, http://www.jgi.doe.gov/whoweare/bioenergy/ bioenergy_4.html.

[11] Ahmed, H.M., personal communication, 7 March 2011, Plant Protection Research Institute, Dokki, Egypt.

[12] Collection of gas over water method, Purdue University, United States of America, http://chemed.chem.purdue.edu/genchem/lab/techniques/gascollect.html.

[13] Korish, E.A., Personal communication, 5 May 2011, Head of Soil and Water Activity of information, Services and Training, Unit of Analysis and Scientific Services, Alexandria University, Alexandria, Egypt. 